\title{
Increased number of peripheral CD8(+) T cells but not eosinophils is associated with late-onset skin reactions caused by bendamustine.
}

\section{$\operatorname{AUTHOR}(S)$ :}

Nishikori, Momoko; Kitano, Toshiyuki; Kobayashi, Masayuki; Hishizawa, Masakatsu; Kitawaki, Toshio; Kondo, Tadakazu; Yamashita, Kouhei; ... Takei, Yusuke; Haga, Hironori; Takaori-Kondo, Akifumi

\section{CITATION:}

Nishikori, Momoko ... [et al]. Increased number of peripheral CD8(+) T cells but not eosinophils is associated with late-onset skin reactions caused by bendamustine. International journal of hematology 2015, 102(1): 53-58

\section{ISSUE DATE:}

2015-07

\section{URL:}

http://hdl.handle.net/2433/202063

\section{RIGHT:}

The final publication is available at Springer via http://dx.doi.org/10.1007/s12185-015-1791-3.; The full-text file will be made open to the public on 02 April 2016 in accordance with publisher's 'Terms and Conditions for Self-Archiving'.; ¿ の論文は出版社版でありません。引用の際には出版社版をご確認じ利用ください。; This is not the published version. Please cite only the published version. 
Increased number of peripheral $\mathrm{CD}^{+} \mathrm{T}$ cells but not eosinophils is associated with late-onset skin reactions caused by bendamustine

Momoko Nishikori ${ }^{1 *}$, Toshiyuki Kitano ${ }^{1 *}$, Masayuki Kobayashi ${ }^{1}$, Masakatsu Hishizawa ${ }^{1}$, Toshio Kitawaki $^{1}$, Tadakazu Kondo ${ }^{1}$, Kouhei Yamashita ${ }^{1}$, Hiroshi Kawabata ${ }^{1}$, Norimitsu Kadowaki ${ }^{1}$, Yusuke Takei $^{2}$, Hironori Haga ${ }^{2}$, Akifumi Takaori-Kondo ${ }^{1}$

${ }^{1}$ Department of Hematology/Oncology, Graduate School of Medicine, Kyoto University; ${ }^{2}$ Department of Pathology, Kyoto University Hospital

54 Shogoin Kawahara-cho, Sakyo-ku, Kyoto, 606-8507, Japan.

* These authors contributed equally to this work.

\section{Corresponding author:}

Momoko Nishikori, Department of Hematology/Oncology, Graduate School of Medicine, Kyoto University, E-mail: nishikor@ kuhp.kyoto-u.ac.jp, Tel: 81-75-751-4964, Fax: 81-75-751-4963

Key words: bendamustine, skin reactions, $\mathrm{CD} 8^{+} \mathrm{T}$ cells, cytomegalovirus 


\section{Abstract}

Bendamustine is a chemotherapeutic drug that has recently come to be used frequently in the treatment of indolent B-cell lymphomas. Skin toxicity is recognized as one of its characteristic side effects, but detailed information on such reactions has not yet been obtained. To clarify the clinical features of skin toxicity associated with bendamustine, we retrospectively analyzed skin reactions that developed in patients treated with bendamustine and rituximab (BR). Of 34 patients treated with $3-6$ cycles of BR, 11 developed late-onset, persistent skin eruptions. These patients demonstrated increases in $\mathrm{CD}^{+} \mathrm{T}$-cell number and $\mathrm{CD}^{+}: \mathrm{CD}^{+}$cell ratio at the end of chemotherapy. In contrast, peripheral eosinophil count was not associated with such adverse events, whereas eosinophil infiltration was frequently observed in the skin. Patients with skin reactions tended to have higher seropositivity of hepatitis B core antibody, and multiplex viral screening PCR of the frozen sera demonstrated cytomegalovirus-DNA in some of the eruption-positive patients. It is speculated that inappropriate activation of $\mathrm{CD}^{+} \mathrm{T}$ cells by latently infected pathogens may be one of the triggers of late-onset skin reactions caused by bendamustine. 


\section{Introduction}

Bendamustine is a unique alkylating agent that has structural similarity to purine analogs. It shows low cross-resistance with other alkylating agents and has been demonstrated to be active for indolent B-cell lymphomas and many other lymphoid malignancies [1-8], but several distinctive toxicities are recognized. Skin toxicity is one of its characteristic adverse effects, and previous clinical studies have suggested that the frequency of skin reactions varies among different countries. For example, skin reactions of any grade were reported in $15-24 \%$ of patients with indolent B-cell lymphomas and mantle cell lymphoma in the StiL NHL-1 and BRIGHT studies [1, 2], but they were reported to have appeared in $46 \%$ of patients with the same disease subtypes in a phase II study in Japan [9]. Although most of the skin reactions are not severe, they are pruritic and often persistent, and affect the quality of life of patients for several months. Presently, there is no detailed clinical information on the skin toxicity of bendamustine, except for some case reports of severe courses [10-13], so we aimed in this study to clarify it by retrospectively analyzing patients treated with bendamustine and rituximab (BR).

\section{Patients and methods}

Thirty-four patients who were treated for 3-6 cycles of BR therapy in Kyoto University Hospital were included in this study. The patients consisted of those with relapsed or refractory indolent B-cell lymphomas and mantle cell lymphoma, with a median age of 63 years (range, 37 to 79 years). They were scheduled to receive $90 \mathrm{mg} / \mathrm{m}^{2}$ x 2 days bendamustine and $375 \mathrm{mg} / \mathrm{m}^{2}$ rituximab every 28 days. The median number of previous therapies applied was 1 (range, 1 to 5): 6 patients had previously received fludarabine treatment, 1 patient had received ibritumomab tiuxetan, and 3 patients had a history of autologous stem cell transplantation. All patients received prophylaxis with sulfamethoxazole-trimetoprim and acyclovir.

Total and differential white blood cells were measured with an automatic cell counter. CD4 and CD8 
positive cells were analyzed by flow cytometry using anti-CD4 and anti-CD8 antibodies (T4-FITC and T8-RD1, Beckman Coulter), and their absolute cell numbers were calculated from the percentage of the cells in total lymphocytes. These data were obtained at two time points in each patient: just before the initiation of BR therapy, and 1 to 2 months after the final administration of BR. Histological analysis was performed on the skin biopsy specimens by standard methods, and anti-CD4 (clone SP35, Ventana), anti-CD8 (clone C8/144B, Dako) and anti-Foxp3 (clone PCH101, eBioscience) antibodies were used for immunohistochemistry. Multiplex polymerase chain reaction (PCR) assays for comprehensive viral screening were performed as described previously [14]. Serum hepatitis B core (HBc) antibody was examined by chemiluminescent enzyme immunoassay (Fuji Revio), which was performed in the routine clinical laboratory. This study was approved by Institutional Review Board of Kyoto University Hospital and performed in accordance of the ethical standards of institutional research committee.

\section{Results}

The overall response rate of BR therapy was $94.1 \%$ (CR in 20 patients, PR in 12 patients), and SD and PD occurred in 1 patient each. Fourteen patients (41.2\%) experienced a skin reaction during or after chemotherapy. In 3 patients, skin reactions appeared transiently; they appeared as an allergy to sulfamethoxazole-trimetoprim, an iodine allergy on receiving contrast-enhanced CT, and non-specific eczema, all of which were resolved within 2 weeks by the cessation of causative drugs and/or topical steroids.

Eleven patients (32.4\%) developed late-onset skin reactions. They appeared during chemotherapy in 7 patients and after the completion of chemotherapy in 4 patients, and persisted for several months (median, 4 months; range, 2 to 15 months; Figure 1). Most of them appeared as a maculopapular rash resembling insect bites (Figure 2); they were pruritic, multifocal, and recurrently induced by stimulations such as alcohol drinking, bathing, and sunburn. Macular erythema (case \#6) and blisters (case \#9) were also 
observed. In case \#8, multiple punched-out ulcers developed in the lower extremities after the typical maculopapular rash had resolved, and this patient was diagnosed with polyarteritis nodosa and was treated with oral steroids for 2 years. Skin biopsies were performed in 3 patients with these late-onset skin reactions, and their histologic diagnoses were spongiotic/interface dermatitis. The elongation of rete ridges with liquefaction degeneration, and perivascular infiltration of lymphocytes and eosinophils were observed (Figure 3a, b). Infiltrating lymphocytes were mainly CD4-positive cells (Figure 3c, d), but a few of them were Foxp3-positive (Figure 3e), suggesting that a relative decrease in regulatory $\mathrm{T}$ cells may play a role in the pathogenesis of skin reactions.

Clinical comparison between the patients with and without late-onset skin reactions showed no significant difference in the age distribution, disease subtypes, or response to chemotherapy (Table 1). Concurrent use of systemic steroids did not clearly affect the frequency of skin reactions either. Laboratory data after the completion of chemotherapy showed no difference in the numbers of total white blood cells, neutrophils, and eosinophils between these groups, but there was a trend for a higher level of

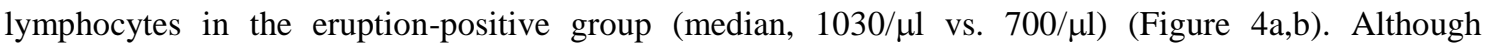
lymphopenia is a well-documented hematological adverse effect of bendamustine, lymphocytes were increased in some patients after chemotherapy. To clarify which subset is responsible for the difference, we analyzed $\mathrm{CD}^{+}$and $\mathrm{CD} 8^{+}$T-cell numbers in 13 patients; 6 eruption-positive and 7 eruption-negative. While $\mathrm{CD}^{+}$cells were invariably suppressed after chemotherapy in both groups (median, $118 / \mu \mathrm{l} v \mathrm{~s}$. $101 / \mu \mathrm{l}), \mathrm{CD} 8^{+}$cells were rather increased, and there was a trend for a higher level of $\mathrm{CD} 8^{+}$cells in the

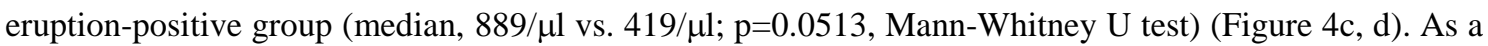
result, the CD8:CD4 T-cell ratio was higher in the eruption-positive patients (median, 7.1 vs. $5.1 ; \mathrm{p}=0.138$, Mann-Whitney U test) (Figure 4d). As for the serum IgG level, there was no significant difference between these groups (Figure 4e).

We hypothesized that the $\mathrm{CD} 8^{+} \mathrm{T}$-cell increase in the patients with late-onset skin reactions may be 
caused by chronic immune activation by some underlying physical conditions. $\mathrm{HBc}$ antibody is an indicator of the past history of hepatitis B virus (HBV) infection, and its presence is recognized as a risk factor for HBV reactivation after immunosuppressive therapy $[15,16]$. We found that $\mathrm{HBc}$ antibody examined before chemotherapy was positive at a higher frequency in the eruption-positive group (36.4\% vs. $16.7 \%$; Table 2). Additionally, we performed comprehensive viral screening by multiplex PCR assays of the frozen sera of 13 patients stored after BR therapy [14]. Although we could not detect HBV-DNA in any of the samples, we detected cytomegalovirus (CMV)-DNA in the sera of 2 out of 6 patients in the eruption-positive group (case \#4 and \#7), but none in the eruption-negative group (Table 2). It is speculated that persistent skin reactions may be associated with the imbalanced activation of $\mathrm{CD}^{+} \mathrm{T}$ cells by latently infected pathogens under $\mathrm{CD} 4^{+} \mathrm{T}$-cell-deficient conditions.

\section{Discussion}

Although bendamustine was first designed in the former German Democratic Republic and used for over 40 years, its toxicity profiles have not been well documented until recently, when it has come to be used broadly for its high effectiveness against indolent B-cell malignancies [17]. Several clinical trials have suggested that skin toxicity is one of the characteristic side effects accompanying bendamustine treatment, while it has often been attributed to the concurrent use of other dermatotoxic drugs such as rituximab, allopurinol, or sulfamethoxazole-trimetoprim. However, bendamustine monotherapy has also been reported to cause skin toxicity, indicating that bendamustine itself has dermatotoxic activity. As few of the skin reactions of bendamustine are severe, no detailed information has been reported, except for some case reports of atypical, detrimental skin reactions [11-13]. In this study, we have focused on the most common skin toxicity of late-onset, pruritic skin eruptions caused by bendamustine.

One of the factors probably causing the late-onset skin reactions with bendamustine is severe $\mathrm{CD} 4^{+}$ T-cell suppression. Pruritic papular eruptions are known as a frequent comorbidity in patients with human 
immunodeficiency virus (HIV) infection [18, 19], and they are related to severe immunosuppression, with $\mathrm{CD}^{+} \mathrm{T}$ cells at less than $200 / \mu 1$ [20]. Pruritic skin papules have also been described in a patient with idiopathic $\mathrm{CD}^{+}$lymphocytopenia [21]. In HIV patients, a decreased number of regulatory T cells (Tregs) is reported to be associated with a disturbed immunological condition, and depletion of Tregs may be one of the common mechanisms of the skin reactions in a $\mathrm{CD} 4^{+}$-deficient state. On the other hand, the peripheral eosinophil count was not associated with adverse events of the skin, although skin biopsy demonstrated eosinophil infiltration at this local site.

Immune reconstitution syndrome (IRS) is an excessive immune reaction triggered by latently infected pathogens that occurs when immunocompromised patients recover immune function [22]. One of the well-known situations in which IRS occurs is in HIV patients at the initiation of combination anti-retroviral therapy (cART). IRS is reported to be caused by many kinds of pathogen, such as herpes viruses, $\mathrm{CMV}, \mathrm{HBV}$, mycobacteria, and cryptococci, and steroid therapy is effective for suppressing these inappropriate immune activations. Late-onset skin reactions of bendamustine are considered to be multifactorial, but it can be speculated that at least some of them develop as IRS-like reactions. In case \#4, CMV-DNA was positive in the serum obtained at the end of BR therapy, but it was not detected in the serum obtained 5 months later when the patient suffered from skin eruption. In IRS, similarly, there is often a time lag between the increase in viral load and immune reactions[22]. Although we could only detect CMV by viral screening PCR of the frozen sera, other cell-associated viruses such as HHV-6 might also be subclinically activated. The difference in the frequency of skin reactions of bendamustine between Asian and Western populations may possibly be explained by the different prevalence of latently infected pathogens in these ethnic groups.

Skin reactions of bendamustine seem to be largely decreased by the concomitant use of $8-12 \mathrm{mg}$ of dexamethasone as an antiemetic, as suggested by the NCCN guidelines (personal communication). Although our retrospective data did not show the protective effect of steroids, we consider that this is 
probably because of the use of smaller doses, and the suppression of $\mathrm{CD}^{+} \mathrm{T}$ cells by steroids possibly avoids the occurrence of skin reactions. However, as $\mathrm{CD} 8^{+} \mathrm{T}$ cells comprise the major population of lymphocytes after BR therapy, there is also concern that the suppression of $\mathrm{CD} 8^{+} \mathrm{T}$ cells by steroids may increase the risk of opportunistic infections.

Our results suggest that the increase in $\mathrm{CD}^{+} \mathrm{T}$ cells is related to adverse skin reactions after bendamustine treatment, but presently it is not clear whether they are only harmful or work preferably for suppressing infections or malignancies under the condition of $\mathrm{CD}^{+}$and B-cell deficiency after $\mathrm{BR}$ therapy. Further information should be accumulated for improved management of the skin toxicity, as well as other complications, of bendamustine.

\section{Acknowledgments}

We are grateful to Dr. Norio Shimizu, Department of Virology, Medical Research Institute, Tokyo Medical and Dental University, and Dr. Naoko Hashimoto and Ms. Rieko Kobayashi, Cell Management Center, Institute of Biomedical Research and Innovation, for comprehensive viral screening test. We also thank Dr. Naoshi Sugimoto, Department of Hematology/Oncology, Kyoto University, for giving us valuable comments. This work was supported partly by grants-in-aid from the Ministry of Education, Culture, Sports, Science, and Technology(24591391), Japan.

\section{Conflict of Interest}

The authors have no conflicts of interest to declare. 


\section{Figure legends}

Figure 1. Schematic illustration of the time course of BR therapy (arrows) and the appearance of skin reaction (shaded square) in each patient. A dotted square in case \#8 indicates the development of periarterial nodosa.

Figure 2. Gross appearance of the skin eruptions developed in the patients with BR therapy (left, case \#4 and right, case \#7).

Figure 3. Histology of biopsied sample of the skin (case \#1). (a) H\&E staining, low-power field (original magnification, x 40); (b) H\&E staining, high-power field (x 400); (c) CD4 staining (x 400); (d) CD8 staining (x 400); and (e) Foxp3 staining (x 400).

Figure 4. Comparison of the peripheral blood cell contents between the patients with and without late-onset skin reactions. (a) Eosinophil counts after BR therapy in the patients with and without late-onset skin reactions. (b) Changes in the lymphocyte number before and after BR therapy. Solid and dotted lines demonstrate the lymphocyte numbers in the patients with $(n=11)$ and without $(n=22)$ late-onset skin reactions, respectively. (A patient without skin reaction was excluded from this data set as she had leukemic disease before chemotherapy.) (c) Changes in the $\mathrm{CD}^{+}$and $\mathrm{CD} 8^{+}$cell numbers before and after BR therapy. Solid and dotted lines demonstrate those in the patients with $(n=6)$ and without $(\mathrm{n}=7)$ late-onset skin reactions, respectively. (d) $\mathrm{CD} 8^{+} \mathrm{T}$ cell counts and $\mathrm{CD} 8^{+}: \mathrm{CD} 4^{+}$cell ratios after BR therapy in the patients with and without late-onset skin reactions. (e) Changes in the serum IgG level before and after BR therapy in the patients with and without late-onset skin reactions, as shown in (c). 
Table 1. Clinical comparison between patients with and without late-onset skin reactions

\begin{tabular}{lcc}
\hline & \multicolumn{2}{c}{ Late-onset skin reactions } \\
\cline { 2 - 3 } & Positive $(\mathrm{n}=11)$ & Negative $(\mathrm{n}=23)$ \\
\hline Age, median (range) & $63(37-76)$ & $63(48-79)$ \\
Histological diagnosis & $8 / 2 / 1$ & $17 / 5 / 1$ \\
FL/MCL/MALT & & \\
Response to chemotherapy & $8 / 2 / 1 / 0$ & $12 / 10 / 0 / 1$ \\
CR/PR/SD/PD & & \\
Concurrent steroid usage & $5 / 6$ & $13 / 10$ \\
yes/no & & 3200 \\
Data at the end of chemotherapy $(\mu \mathrm{l})$ & 3400 & $(1300-8200)$ \\
WBC, median (range) & $(1300-6100)$ & 1612 \\
Neutrophils, median (range) & 1584 & $(130-6560)$ \\
& $(756-4465)$ & 700 \\
Lymphocytes, median (range) & 1030 & 189 \\
Eosinophils, median (range) & $(143-2255)$ & $(0-1184)$ \\
\hline
\end{tabular}

Abbreviations: FL, follicular lymphoma; MCL, mantle cell lymphoma; MALT, extranodal marginal zone lymphoma of mucosa-associated lymphoid tissue. 
Table 2. Results of serological analysis

\begin{tabular}{lcc}
\hline & \multicolumn{2}{c}{ Late-onset skin reactions } \\
\cline { 2 - 3 } & Positive & Negative \\
\hline HBc antibody positive & $4 / 11$ & $4 / 23$ \\
& $(36.4 \%)$ & $(17.4 \%)$ \\
\hline CMV-DNA positive* & $2 / 6$ & $0 / 7$ \\
& $(33.3 \%)$ & $(0 \%)$ \\
\hline
\end{tabular}

*Analysis of the frozen sera stocked at the completion of BR therapy. 


\section{References}

1. Rummel MJ, Niederle N, Maschmeyer G et al. Bendamustine plus rituximab versus CHOP plus rituximab as first-line treatment for patients with indolent and mantle-cell lymphomas: an open-label, multicentre, randomised, phase 3 non-inferiority trial. Lancet 2013; 381: 1203-1210.

2. Flinn IW, van der Jagt R, Kahl BS et al. Randomized trial of bendamustine-rituximab or R-CHOP/R-CVP in first-line treatment of indolent NHL or MCL: the BRIGHT study. Blood 2014; 123: 2944-2952.

3. Ohmachi K, Niitsu N, Uchida T et al. Multicenter phase II study of bendamustine plus rituximab in patients with relapsed or refractory diffuse large B-cell lymphoma. J Clin Oncol 2013; 31: 2103-2109.

4. Fischer K, Cramer P, Busch R et al. Bendamustine combined with rituximab in patients with relapsed and/or refractory chronic lymphocytic leukemia: a multicenter phase II trial of the German Chronic Lymphocytic Leukemia Study Group. J Clin Oncol 2011; 29: 3559-3566.

5. Fischer K, Cramer P, Busch R et al. Bendamustine in combination with rituximab for previously untreated patients with chronic lymphocytic leukemia: a multicenter phase II trial of the German Chronic Lymphocytic Leukemia Study Group. J Clin Oncol 2012; 30: 3209-3216.

6. Damaj G, Gressin R, Bouabdallah K et al. Results from a prospective, open-label, phase II trial of bendamustine in refractory or relapsed T-cell lymphomas: the BENTLY trial. J Clin Oncol 2013; 31: 104-110.

7. Moskowitz AJ, Hamlin PA, Jr., Perales MA et al. Phase II study of bendamustine in relapsed and refractory Hodgkin lymphoma. J Clin Oncol 2013; 31: 456-460.

8. Intlekofer AM, Younes A. From empiric to mechanism-based therapy for peripheral $\mathrm{T}$ cell lymphoma. Int J Hematol 2014; 99: 249-262.

9. Ohmachi K, Ando K, Ogura M et al. Multicenter phase II study of bendamustine for relapsed or refractory indolent B-cell non-Hodgkin lymphoma and mantle cell lymphoma. Cancer Sci 2010; 101: 2059-2064.

10. Malipatil B, Ganesan P, Sundersingh S, Sagar TG. Preliminary experience with the use of bendamustine: a peculiar skin rash as the commonest side effect. Hematol Oncol Stem Cell Ther 2011; 4: 157-160.

11. Alamdari HS, Pinter-Brown L, Cassarino DS, Chiu MW. Severe cutaneous interface drug eruption associated with bendamustine. Dermatol Online J 2010; 16: 1.

12. Gavini A, Telang GH, Olszewski AJ. Generalized purpuric drug exanthem with hemorrhagic plaques following bendamustine chemotherapy in a patient with B-prolymphocytic leukemia. Int $\mathrm{J}$ Hematol 2012; 95: 311-314.

13. Lambertini M, Del Mastro L, Gardin G et al. Stevens-Johnson syndrome after treatment with 
bendamustine. Leuk Res 2012; 36: e153-154.

14. Ito K, Shimizu N, Watanabe $\mathrm{K}$ et al. Analysis of viral infection by multiplex polymerase chain reaction assays in patients with liver dysfunction. Intern Med 2013; 52: 201-211.

15. Evens AM, Jovanovic BD, Su YC et al. Rituximab-associated hepatitis B virus (HBV) reactivation in lymphoproliferative diseases: meta-analysis and examination of FDA safety reports. Ann Oncol 2011; 22: 1170-1180.

16. Lan JL, Chen YM, Hsieh TY et al. Kinetics of viral loads and risk of hepatitis B virus reactivation in hepatitis B core antibody-positive rheumatoid arthritis patients undergoing anti-tumour necrosis factor alpha therapy. Ann Rheum Dis 2011; 70: 1719-1725.

17. Cheson BD, Wendtner CM, Pieper A et al. Optimal use of bendamustine in chronic lymphocytic leukemia, non-Hodgkin lymphomas, and multiple myeloma: treatment recommendations from an international consensus panel. Clin Lymphoma Myeloma Leuk 2010; 10: 21-27.

18. Matthews SN, Cockerell CJ. Prurigo nodularis in HIV-infected individuals. Int J Dermatol 1998; 37: 401-409.

19. Liautaud B, Pape JW, DeHovitz JA et al. Pruritic skin lesions. A common initial presentation of acquired immunodeficiency syndrome. Arch Dermatol 1989; 125: 629-632.

20. Afonso JP, Tomimori J, Michalany NS et al. Pruritic papular eruption and eosinophilic folliculitis associated with human immunodeficiency virus (HIV) infection: a histopathological and immunohistochemical comparative study. J Am Acad Dermatol 2012; 67: 269-275.

21. Wakeel RA, Urbaniak SJ, Armstrong SS et al. Idiopathic CD4+ lymphocytopenia associated with chronic pruritic papules. Br J Dermatol 1994; 131: 371-375.

22. Shiohara T, Kurata M, Mizukawa Y, Kano Y. Recognition of immune reconstitution syndrome necessary for better management of patients with severe drug eruptions and those under immunosuppressive therapy. Allergol Int 2010; 59: 333-343. 


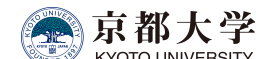

Figure 1

$\# 1 \downarrow \downarrow \downarrow \downarrow \downarrow \downarrow$

$\# 2 \downarrow \downarrow \downarrow \downarrow \downarrow \downarrow \downarrow$

$\# 3 \downarrow \downarrow \downarrow \downarrow \downarrow \downarrow \downarrow \downarrow$

$\# 4 \downarrow \downarrow \downarrow \downarrow \downarrow \downarrow$

$\# 5 \downarrow \downarrow \downarrow \downarrow \downarrow \downarrow \downarrow$

\#6 $\downarrow \downarrow \frac{1}{1} \downarrow$

$\# 7 \downarrow \downarrow \downarrow \downarrow \downarrow \downarrow \downarrow \downarrow$

$\# 8 \downarrow \downarrow \downarrow \downarrow \downarrow \downarrow \downarrow$

$\# 9 \downarrow \downarrow \downarrow$

$\# 10 \downarrow \downarrow \downarrow \downarrow \downarrow \downarrow \downarrow$

$\# 11 \downarrow \downarrow \downarrow \downarrow \downarrow \downarrow$

\begin{tabular}{cccccc}
1 & & $\mid$ & & & \\
\hline 0 & 3 & 6 & 9 & 12 & 15
\end{tabular}

months 
Figure 2
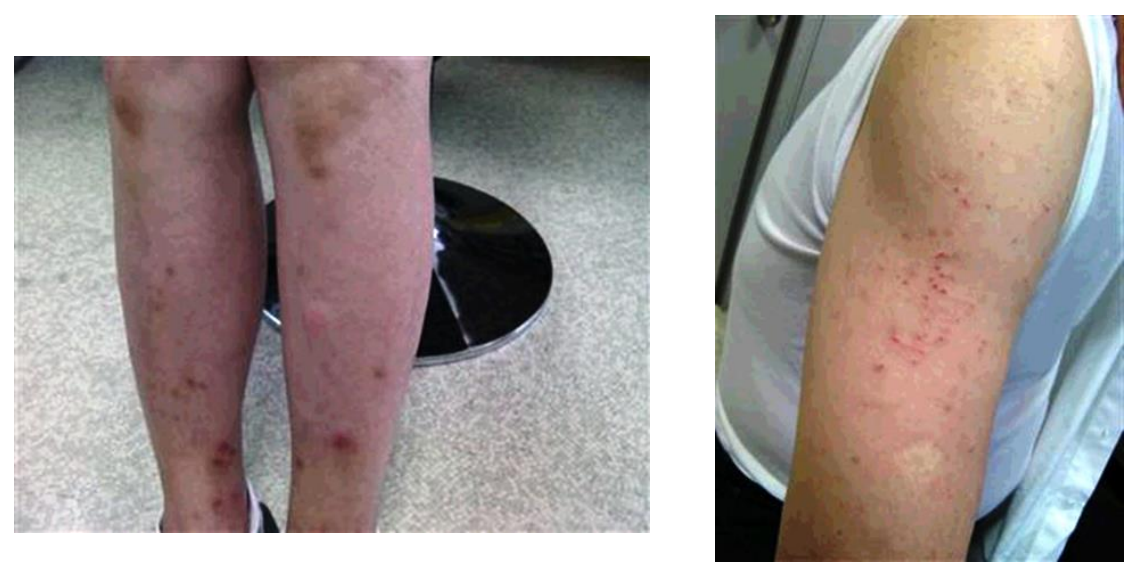


\section{Figure 3}
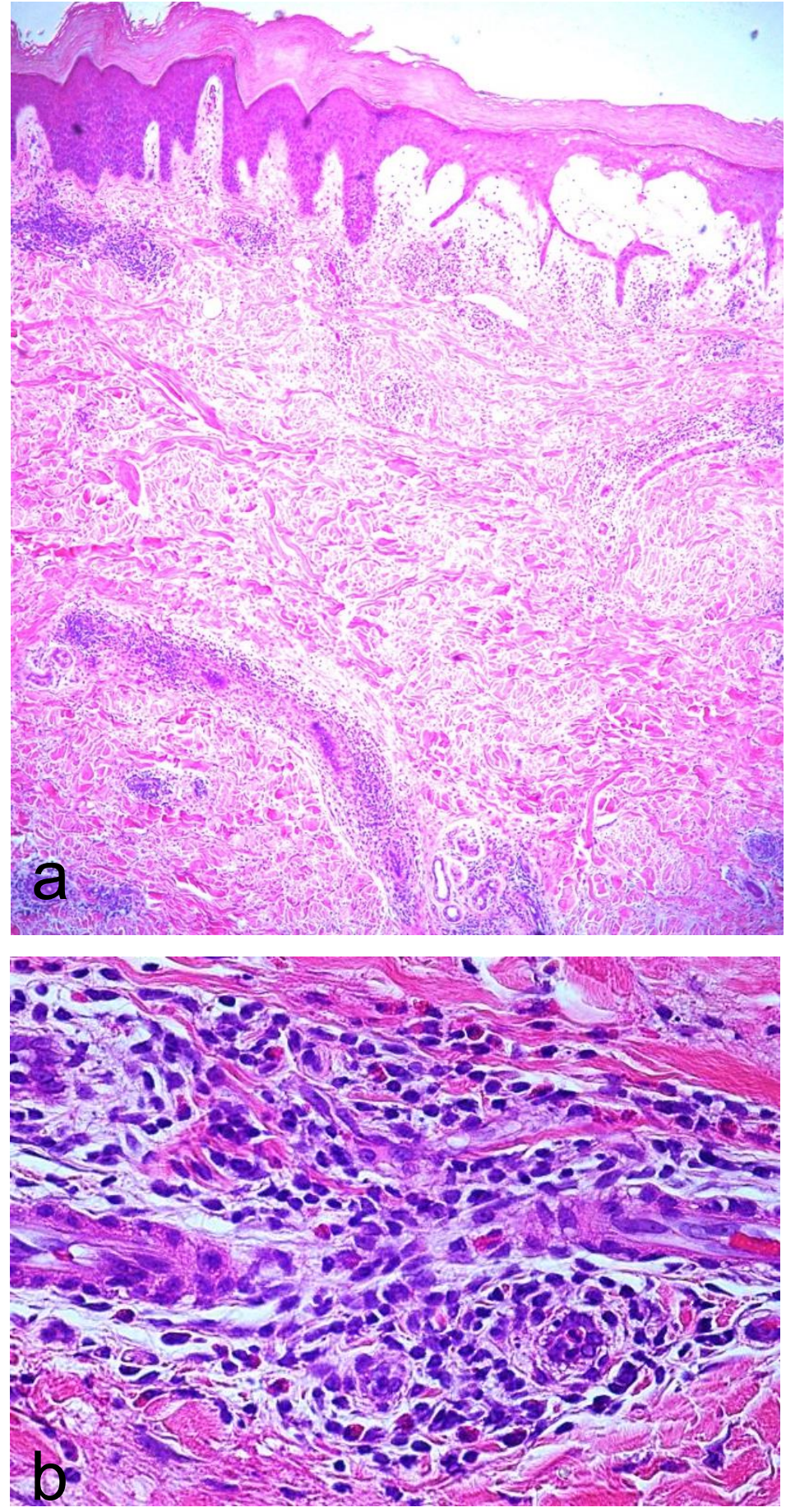
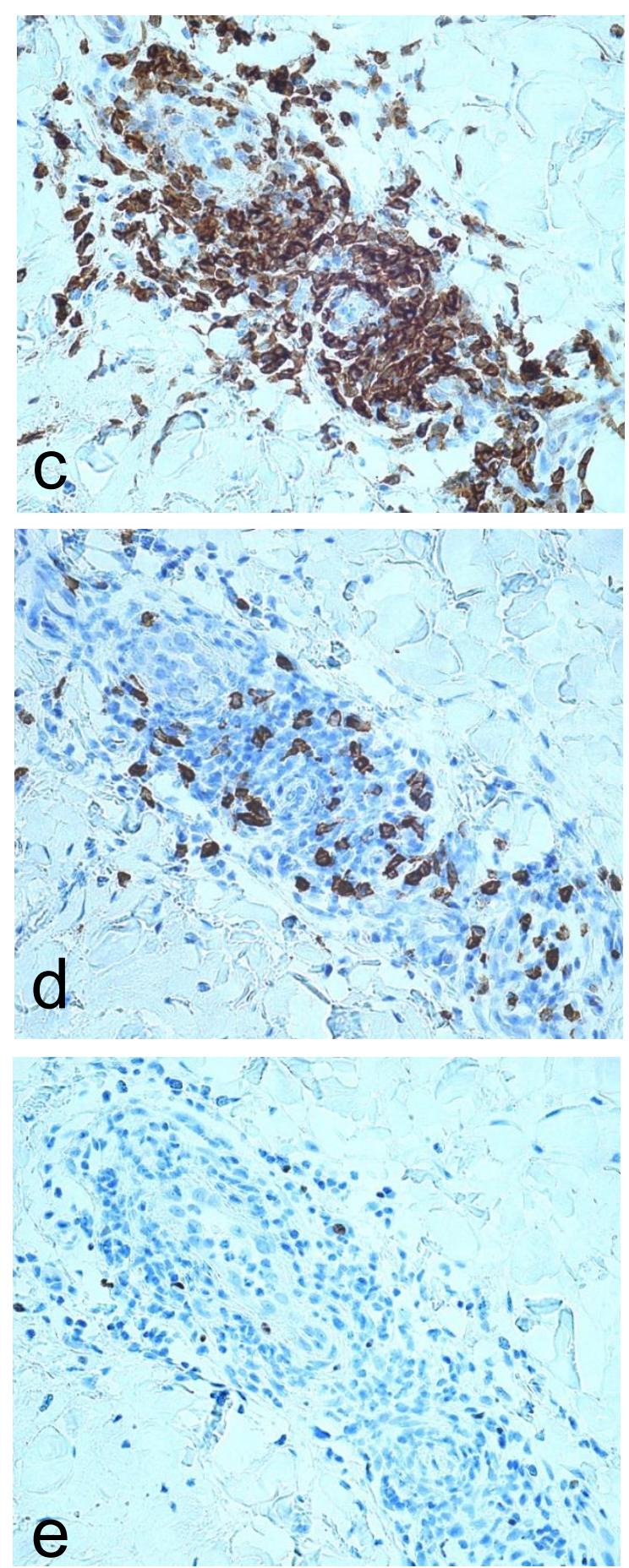
Figure 4

(a)

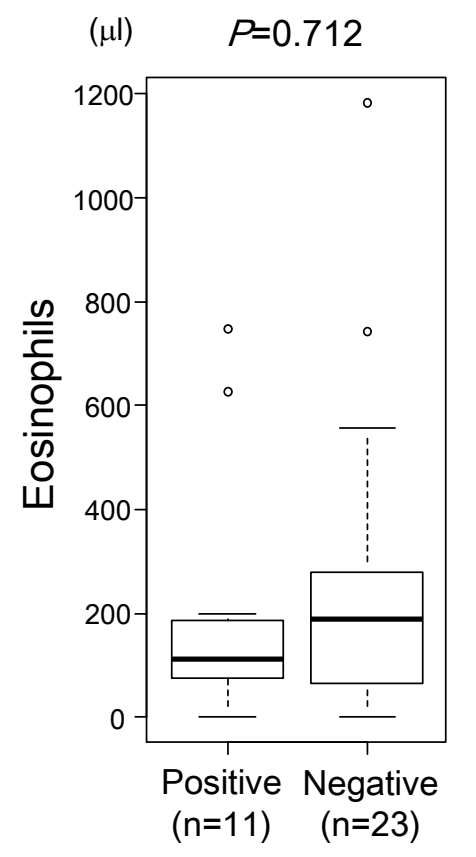

Late-onset skin reactions (b)

( $\mu \mathrm{l})$

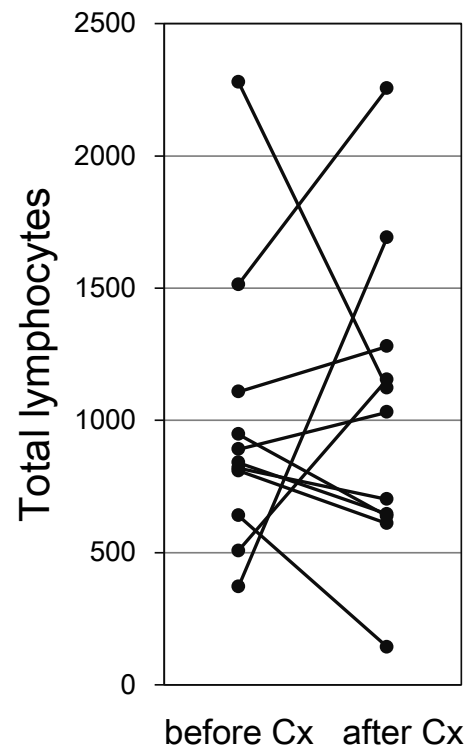

Positive $(n=11)$ (e)

( $\mu \mathrm{l})$

2500

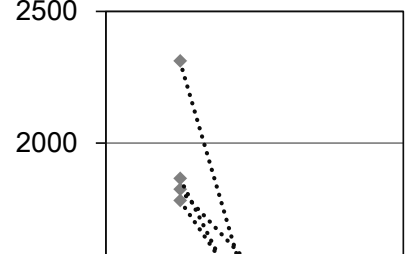

1500

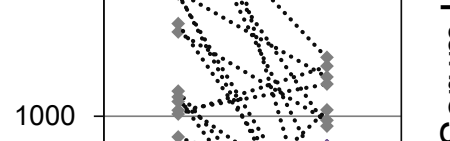

0

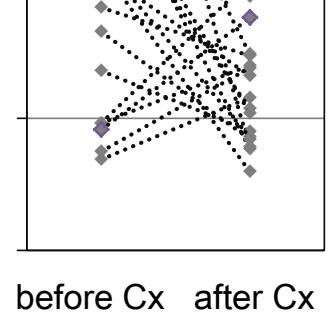

Negative $(n=22)$ (mg/dl)

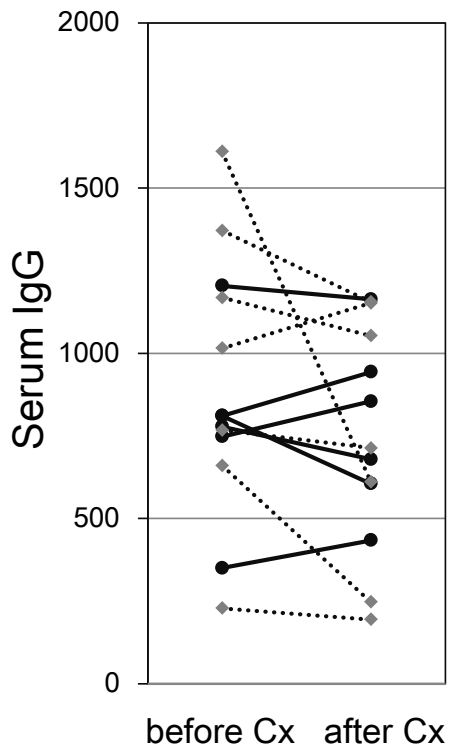

(c)

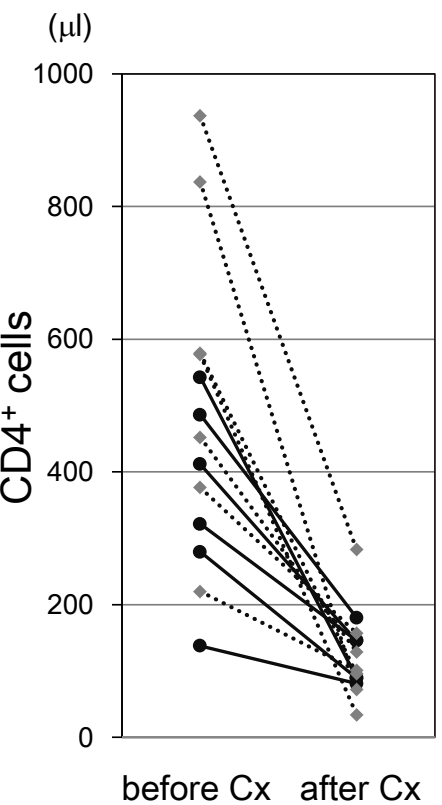

(d)

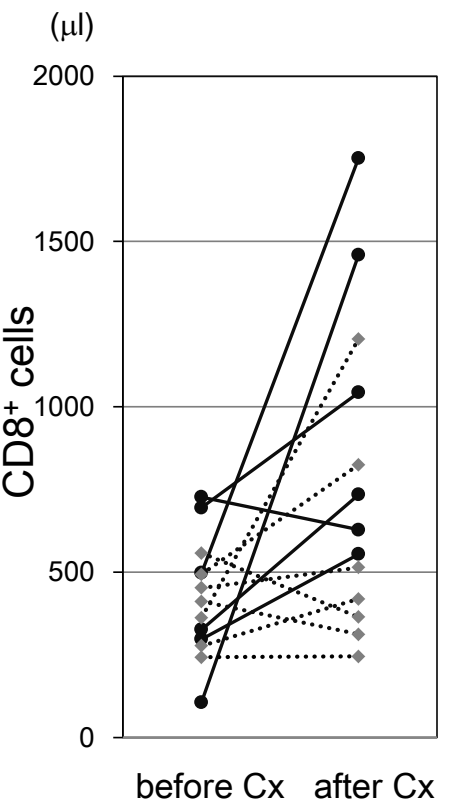

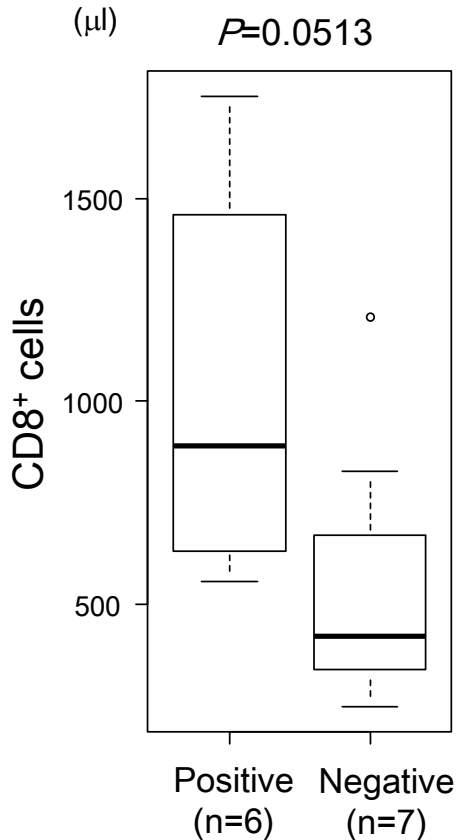

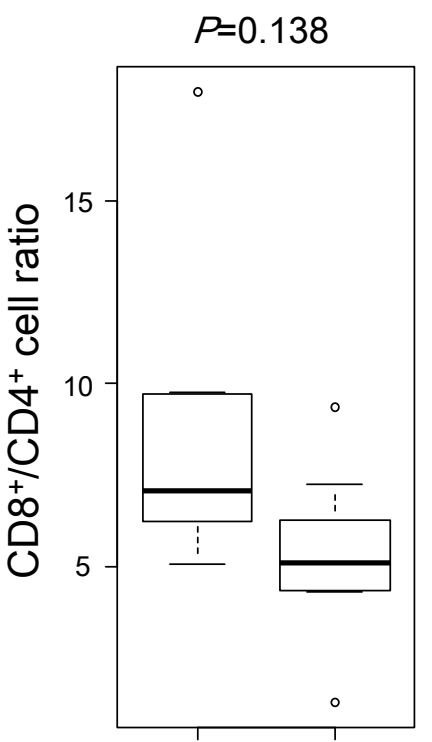

Positive Negative $(\mathrm{n}=6) \quad(\mathrm{n}=7)$

Late-onset skin reactions 